\title{
Intervenable factors associated with suicide risk in transgender persons: a respondent driven sampling study in Ontario, Canada
}

\author{
Greta R. Bauer ${ }^{1 *}$, Ayden I. Scheim¹, Jake Pyne ${ }^{2}$, Robb Travers ${ }^{3}$ and Rebecca Hammond ${ }^{4}$
}

\begin{abstract}
Background: Across Europe, Canada, and the United States, 22-43\% of transgender (trans) people report a history of suicide attempts. We aimed to identify intervenable factors (related to social inclusion, transphobia, or sex/ gender transition) associated with reduced risk of past-year suicide ideation or attempt, and to quantify the potential population health impact.
\end{abstract}

Methods: The Trans PULSE respondent-driven sampling (RDS) survey collected data from trans people age 16+ in Ontario, Canada, including 380 who reported on suicide outcomes. Descriptive statistics and multivariable logistic regression models were weighted using RDS II methods. Counterfactual risk ratios and population attributable risks were estimated using model-standardized risks.

Results: Among trans Ontarians, $35.1 \%$ (95 \% Cl: 27.6, 42.5) seriously considered, and $11.2 \%$ (95 \% Cl: 6.0, 16.4) attempted, suicide in the past year. Social support, reduced transphobia, and having any personal identification documents changed to an appropriate sex designation were associated with large relative and absolute reductions in suicide risk, as was completing a medical transition through hormones and/or surgeries (when needed). Parental support for gender identity was associated with reduced ideation. Lower self-reported transphobia $\left(10^{\text {th }}\right.$ versus $90^{\text {th }}$ percentile) was associated with a $66 \%$ reduction in ideation ( $\mathrm{RR}=0.34,95 \% \mathrm{Cl}: 0.17,0.67$ ), and an additional $76 \%$ reduction in attempts among those with ideation ( $\mathrm{RR}=0.24 ; 95 \% \mathrm{Cl}: 0.07,0.82$ ). This corresponds to potential prevention of 160 ideations per 1000 trans persons, and 200 attempts per 1,000 with ideation, based on a hypothetical reduction of transphobia from current levels to the $10^{\text {th }}$ percentile.

Conclusions: Large effect sizes were observed for this controlled analysis of intervenable factors, suggesting that interventions to increase social inclusion and access to medical transition, and to reduce transphobia, have the potential to contribute to substantial reductions in the extremely high prevalences of suicide ideation and attempts within trans populations. Such interventions at the population level may require policy change.

Keywords: Social exclusion, Transgender, Transsexual, Suicide, Suicidal behaviour, Social determinants of health, Transphobia

\footnotetext{
* Correspondence: greta.bauer@schulich.uwo.ca

${ }^{1}$ Epidemiology \& Biostatistics, Schulich School of Medicine \& Dentistry, The University of Western Ontario, London, Canada

Full list of author information is available at the end of the article
} 


\section{Background}

Trans (transgender or transsexual) people, who may represent up to $0.5 \%$ of the adult population [1], have an extremely high prevalence of suicide ideation and attempts. Studies in Canada, Europe, and the United States have reported suicide attempt prevalences within the trans population that range from 22 to $43 \%$ over the lifetime and 9 to $10 \%$ for the past year [2-7]. In contrast, $3.7 \%$ of all Can adians had seriously considered [8], and $0.6 \%$ attempted [9], suicide in the past year. While completed suicide rates among trans people are unknown [10], a history of attempted suicide is the strongest predictor of completed suicide across multiple populations [11]. Demographic factors predictive of suicide attempts in the Canadian population overall include female sex, youth, chronic illness, lack of religiosity, and being unmarried [9]. These predictors may not hold within trans populations; for instance, among trans Ontarians, ideation and attempts did not differ by gender identity [2]. Moreover, while identification of demographic risk factors is helpful for targeting interventions, they are largely non-modifiable. There is an urgent need to identify intervenable risk and protective factors [12].

To date, most trans suicide research has been descriptive, or has assessed predictors of any lifetime suicide attempts $[6,7,13]$. This limits applicability of results to suicide prevention, because predictors of lifetime versus recent suicide risk, and of ideation versus attempts, may differ. Other studies have focused on patients seeking care for medical transition $[14,15]$, who are not representative of the entire trans population [16]. Recent longitudinal studies demonstrate reductions in psychological distress following medical transition $[17,18]$. Therefore, barriers to accessing transition-related care [19] may contribute to increased suicide ideation and attempts. However, among those who have had hormonal treatment and/or sex reassignment surgery, suicide attempts and deaths remain elevated relative to the broader population $[15,20]$. Thus, it appears that factors other than gender dysphoria (distress or discomfort with one's natal sex) contribute to increased suicide risk in trans populations.

While not all trans people experience profound distress regarding their embodiment, they nearly universally report some degree of social exclusion and transphobia [21]. Trans people are subjected to invisibility in institutional settings [22], high levels of discrimination and rejection [21, 23], harassment and violence [24-26], and poverty [7, 27]. Trans-related social exclusion has been associated with increased lifetime and past-year suicide attempts $[2,6,28]$, while social and family support appear to be protective $[2,29]$. Determinants of suicide risk in the broader population, including depression, substance misuse, and poverty $[9,10]$ are also elevated among trans persons $[6,30,31]$, but are consistently attributed to social exclusion and victimization [23, 25, 28, 32, 33]. Social exclusion, victimization, and trauma have been identified as key contributors to suicide disparities across marginalized populations, including sexual minorities [34-38] and Indigenous peoples [38-41].

The current study sought to identify intervenable social factors associated with suicide risk reduction for trans people.

\section{Theoretical model}

We present a conceptual model (Fig. 1) for two outcomes: past-year serious consideration of suicide, and - among those considering - past-year attempt. This approach reflected the possibility that factors impacting ideation and attempts may differ, as well as the pragmatic desire to both prevent suicidal ideation and to inform crisis interventions among those who are suicidal.

Variables were included as socio-demographic or background factors for the following reasons: 1) they are not amenable to change through intervention in our study population, either because they are unchangeable or because they occurred prior to age $16 ; 2$ ) they are unlikely to be a result of the intervenable factors in the model, and 3) they are known or hypothesized to be associated with suicide ideation or attempts. Background factors must be controlled for as confounders in order to explore the impact of intervenable factors, so that differences observed for other factors are not based simply on differences in socio-demographic composition, illness, or history of childhood abuse.

Variables representing modifiable factors that may be targeted by potential interventions for suicide prevention within trans populations fell within three major constructs: social inclusion, transphobia (including enacted and internalized stigma, as well as violent victimization), and sex/gender transition. Their roles reflect minority stress [42], as they represent discrimination or acceptance, inclusion or exclusion, and barriers to full social participation. Moreover, all thirteen intervenable factors are social or medical determinants of health that are potentially intervenable through policy, social and/or medical intervention, but suggest different strategies. Thus, they are considered individually in this analysis rather than as overall constructs. For example, within the construct of social inclusion, interventions designed to increase parental support for gender identity or expression (e.g., family therapy, social media campaigns) would differ from those to increase identity document concordance (e.g., policy change on requirements for sex designation changes (or removal of sex designations altogether) at the federal and state/provincial levels).

Interventions on these factors have the potential to impact suicide ideation and attempts through multiple pathways. Suicide researchers have proposed models of suicidal behaviour, which focus on proximal determinants 


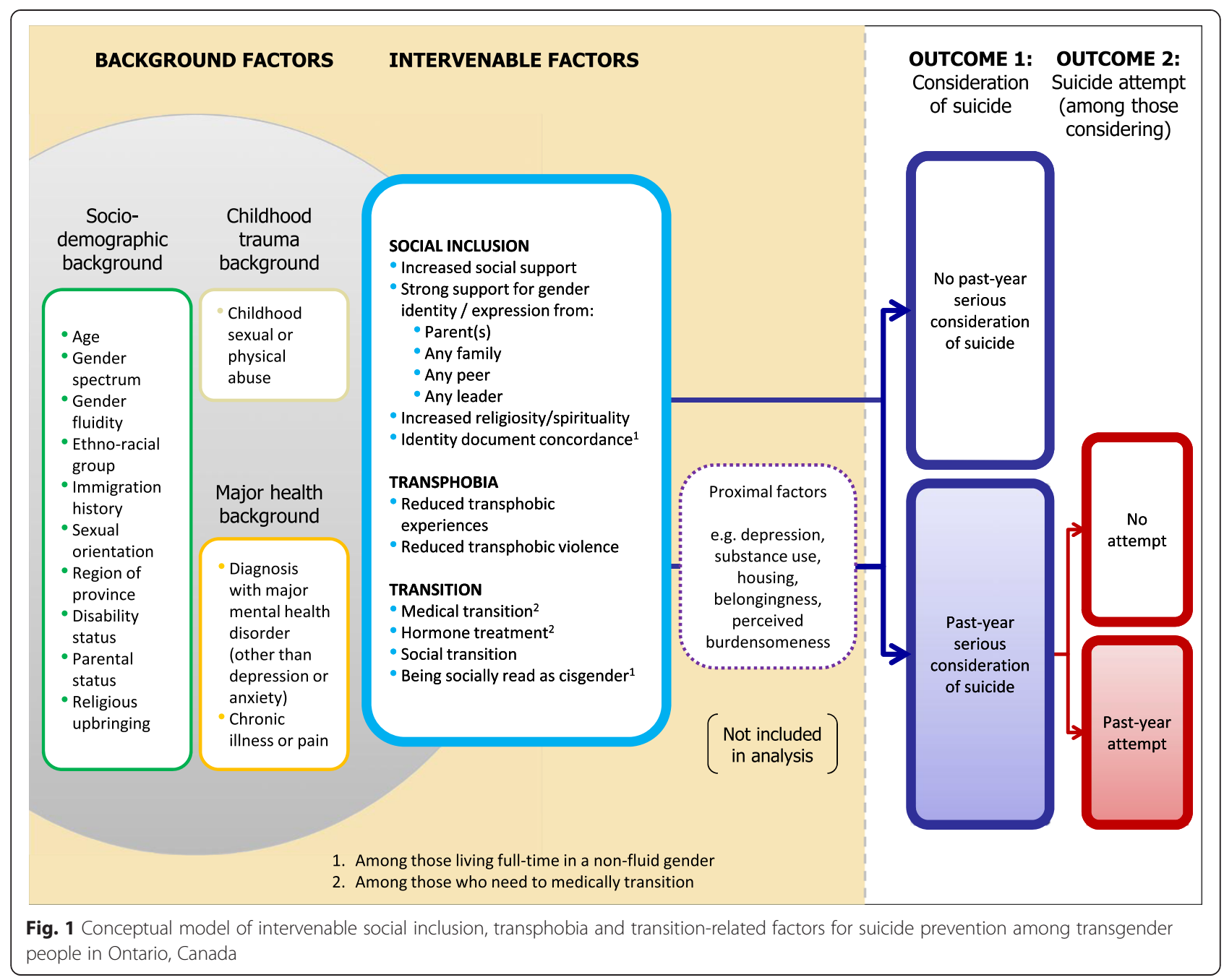

of ideation and attempts. Prominent among them is Joiner's Interpersonal Theory of Suicide [43, 44], which accounts for a wide range of known risk factors for suicidal behaviour via three primary constructs. Suicide ideation is attributed to thwarted belongingness (resulting from social isolation) and perceived burdensomeness (e.g., resulting from family conflict or illness), and acquired capability is required for suicidal ideation to engender suicidal intent and attempts. The capability to overcome the natural disinclination to physical pain and death is acquired through previous exposure to fear and/or pain. Distal factors are posited to increase suicide risk by contributing to these proximal constructs [44]. Such distal factors are the focus of our analysis, but we include proximal factors in Fig. 1 to explicate this conceptualization. Similarly, given the frequency of transphobic experiences [21] and their profound effects on depression [30-32], housing [45], and access to services [22], we also included most of the variables traditionally defined as psychosocial risk factors as proximal factors. Together, these may mediate the effects of transphobia and other intervenable variables on ideation and/or attempts through a multitude of possible pathways that may be explored in future research.

\section{Methods}

\section{Study sample}

Data were collected via respondent-driven sampling (RDS) in 2009-2010 as part of the Trans PULSE Project, a community-based research study in Ontario, Canada's most populous province. To be eligible, participants had to live, work or receive health care in Ontario, be age 16 or over, and identify as trans, broadly defined. Participants held a range of gender identities and were not required to have begun a social or medical sex/gender transition.

RDS is a method that combines systematic chain-referral sampling with statistical analysis strategies that account for differential levels of connectedness as well as nonindependence within recruitment chains. This method was chosen as trans persons in Ontario were at least 
moderately networked, either in person or electronically, but constituted a hidden population that could not be randomly sampled. Moreover, given the lack of data on trans people, there was community motivation to participate, including to recruit others. Sampling began with 16 initial seeds, with 22 additional seeds enrolled once it was certain that sufficient recruitment chain length could be obtained. Each participant could recruit additional participants using a tracked coupon system, wherein three coupons were issued to each participant for distribution to eligible individuals. This allowed the research team to identify the network structure (i.e., who recruited whom) while allowing participants to remain anonymous if desired. Data collection continued for one year $(n=433)$, with a maximum chain length of ten waves. A network diagram of the sample is presented in Fig. 2. Our analysis is based on 380 participants (87.8 \%) who completed items on past-year suicide ideation and attempts. Ethics approval for the project was provided by Research Ethics Boards at The University of Western Ontario and Wilfrid Laurier University.

\section{Survey and measures}

Measures were derived from self-report data collected through a multi-mode survey (with visually identical online or paper versions), which could be completed anonymously and typically took 60 to 90 minutes. The survey was pretested by 16 members of the project's Community Engagement Team for content validity, clarity and length. A copy of the survey is available online (http://transpulseproject.ca/resources/trans-pulse-survey/).

\section{Outcomes}

Past-year suicidal ideation was coded from items that asked participants "Have you ever seriously considered committing suicide or taking your own life?" and "If yes, has this happened in the past 12 months?" Similar follow-up questions for those who indicated ideation asked "Have you ever attempted to commit suicide or tried taking your own life?" and "If yes, did this happen in the past 12 months?"

\section{Background variables}

Age, disability status, parental status, and chronic illness/ pain were indicated by participant self-report. Gender spectrum was coded into two categories that each represent a spectrum of identities. Female-to-male spectrum individuals were those assigned female at birth, but who now identify as men or another non-female identity (e.g., genderqueer, bigender); similarly, male-to-female spectrum participants were those assigned male at birth who now identify as women, trans girls, two-spirit, or other

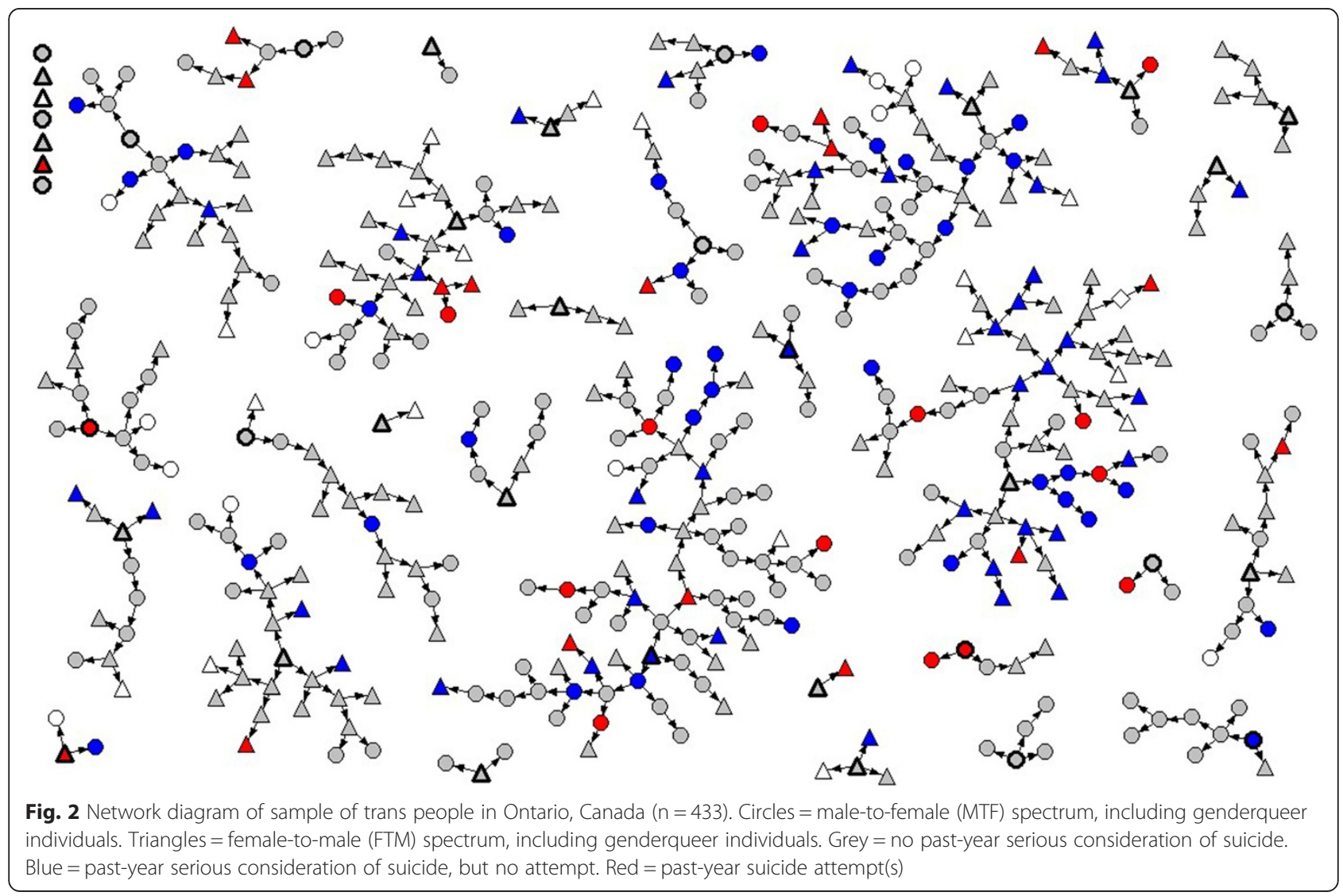


non-male identities. Gender fluidity was coded as a separate dichotomous measure from a check-all-that-apply identity item into two categories: holding a more conventional gender identity (male or primarily masculine, female or primarily feminine), or only gender-fluid or third-gender identities. Ethno-racial group was comprised of three groups: participants were grouped as Aboriginal if they indicated they were First Nations, Métis, or Inuit, or another Indigenous ethnicity; non-Aboriginal participants were classified as white or racialized based on an ethno-racial background item, a write-in question describing background, and indication as to whether or not they were perceived by others as a person of colour. In Ontario, the term "racialized" is preferred over racial minority, visible minority, person of colour or non-White as it expresses race as a social construct rather than a description on perceived biological traits" [46]. Immigration history was approximated by self-report of whether the participant was born in Canada. Sexual orientation was coded as sexual minority based on either identification as gay, lesbian or bisexual/pansexual, or having a pastyear sex partner of the same gender. Region of province was classified based on first letter of postal code. Strong religious upbringing was defined as responding "quite" or "extremely" to the question "How religious or faith-based was your upbringing?" Childhood abuse prior to age 16 was indicated in two items describing physical and sexual abuse experiences. Major mental health disorders were coded using a selfreported checklist based on any prior diagnosis (e.g., bipolar disorder, schizophrenia, borderline personality disorder). Depression and anxiety disorders were excluded, as they are more likely to result from intervenable factors under study, and we hypothesized they would partially mediate their effects on suicide ideation or attempt; if we were to control for these mediators we would then remove a portion of the causal effect and would produce estimates for the effects of our intervenable factors as enacted only through pathways other than depression or anxiety.

\section{Intervenable variables - social inclusion}

Social support was assessed using the 19-item Medical Outcomes Study Social Support Scale [47]. Items were averaged, with possible scale values from 1 to 5 (Cronbach $\alpha=0.97$ ). Strong support for gender was coded for participants' parents by combining self-report of either "very strong" support for gender identity or expression experienced from a parent or parents, or (for those who were not out to their parents) self-report of expectation of such support. Other gender support variables were similarly coded. "Peers" averaged completed items on friends, co-workers, or classmates, and "Leaders" on schools, teachers, supervisors or employers. Current religiosity or spirituality was measured on a 6-point Likert scale ranging from "not at all" to "extremely". Having one or more identity documents concordant with lived gender was coded for the participant sub-group who had socially transitioned and lived full-time in a male/masculine or female/feminine gender, based on having at least one document with a sex/gender designation (" $\mathrm{M}$ " or " $\mathrm{F}$ ") matching one's lived gender. Identity documents included federal and provincial identification (e.g. drivers license, passport, Indian Status card, military ID).

\section{Intervenable variables -transphobia}

Transphobia was assessed using an 11-item scale [21]; it included items on enacted and internalized stigma as well as victimization, such as police harassment or feeling that being trans hurt or embarrassed one's family. Items were summed, with possible values ranging from 0 to 33 (Cronbach $\alpha=0.81$ ). Transphobic harassment and violence was defined as self-report of physical or sexual assault for being trans (analogous to assault as a hate crime); report of verbal harassment or threats related to being trans, but not of assault; and report of none of these.

\section{Intervenable variables -transition}

Medical transition status was self-reported as having completed a medical transition (self-defined), being in the process, planning to transition but not yet having begun, and either not planning, being unsure, or indicating that the concept of "transition" did not apply. Completing a medical transition involved varying hormone and/or surgical treatments [16]. Hormone use was selfreported. Social transition status was coded as living in one's felt gender full-time, part-time, or not at all. Being perceived as cisgender (non-trans) was coded for those living full-time in a non-fluid gender, based on a survey item that asked how often others knew you were trans without being told.

\section{Statistical analysis}

Since eligible trans persons who knew fewer potential participants were less likely to be sampled than those with large network sizes, RDS II weights [48] were calculated based on the inverse of each participant's degree (personal network size), rescaled to sum to the total sample size of 433. This approach has been shown to produce frequency estimates that are asymptotically unbiased [49]. Here weighted statistics can be interpreted to apply to the population of networked (know at least one other eligible person) trans people age 16 and over in Ontario. All analyses were weighted, and adjusted for clustering by shared recruiter to account for non-independence within recruitment chains. Weighted frequencies or means, along with $95 \%$ confidence intervals, were calculated for all background and potential intervention variables using SAS version 9.3 [50]. 
Prior to regression, simple imputation was used for background variables to reduce data loss in a complete case analysis. Of 380 participants with outcome data, 30 were missing data for one background covariate and 5 for more than one.

Multivariable logistic regression models were fitted for each intervenable factor variable separately, controlling for all background variables, using SAS-callable SUDAAN version 11.0 [51]. Thus, 13 logistic regression models were fitted for the 13 intervenable factor variables for the suicidal ideation outcome, and an additional 13 models for the suicide attempt outcome; all models similarly controlled for background variables, but not for other intervenable variables, as mediated pathways between these variables are unknown. A domain analysis was used in order to limit the second analysis to the sample subgroup with suicidal ideation.

All categorical variables were dummy-coded to allow for independent estimation of effects for each group. Reference categories were chosen so that contrasts reflected effects in the direction of desired potential intervention effects (e.g., protecting from assault, increasing social support). Continuous variables were entered into the models as continuous. Since average marginal risks are estimated for specific points in the distribution (as if the entire trans population - standardized to the background variables was at that level), the $10^{\text {th }}$ and $90^{\text {th }}$ percentiles were used as points for estimation since participant values did not necessarily cover the range of a scale and the extremes may not be achievable with any intervention (e.g., no transphobia would require not even having heard once that trans people were not normal).

Model-standardized risks and risk ratios for pastyear suicidal ideation and attempts (standardized to the weighted sample or subsample on all background factors) were estimated for each of the thirteen intervenable variables under the counterfactual conditions where all participants were exposed or alternately all were unexposed to a dichotomous intervenable factor, or to an intervention target and reference level of a categorical factor. For continuous variables, these counterfactual risks were estimated for the $10^{\text {th }}$ and $90^{\text {th }}$ percentile levels. Standardized risks and risk ratios, and their $95 \%$ confidence intervals, were calculated by Graubard and Korn's method [52] using the ADJRR option in SUDAAN PROC RLOGIST [51]. Where effects were statistically significant for a variable, counterfactual population attributable risks (cPARs) were then calculated by taking the weighted prevalence of the outcome in the sample (factual) and subtracting the model-standardized risk (counterfactual) based on having the entire population at intervention target levels of the exposure. These represent the potential proportion of the trans population affected (e.g., outcome averted) under the intervention target condition (e.g., all have parental support for gender). Counterfactual population attributable risk proportions (c\%PARs) were similarly estimated by dividing cPAR by the weighted prevalence of the outcome in the sample; these represent the proportion of cases potentially averted within the trans population. C\%PARs for different variables will sum to more than $100 \%$, given that a case of ideation or suicide attempt could be prevented through multiple means.

\section{Results}

Means or frequencies for sociodemographics and background covariates are presented in Table 1. Frequencies for intervenable variables and past-year suicide ideation and attempt are presented in Table 2 . In the past year, $35.1 \%$ (95 \% CI: 27.6, 42.5) had seriously considered suicide, and $11.2 \%$ (95 \% CI: 6.0, 16.4) reported that they had attempted it.

Findings on model-standardized risks are presented in Table 3 for suicide ideation and in Table 4 for suicide attempts (among those with ideation), along with modelstandardized relative risks and population attributable risks. Average relative effects on individuals, and at a trans population level, were sometimes strong. High levels of social support (90th percentile) versus low levels $\left(10^{\text {th }}\right.$ percentile) were significantly associated with a $49 \%$ reduction in suicide ideation $(\mathrm{RR}=0.51 ; 95 \% \mathrm{CI}$ : $0.28,0.94)$, and with a further $82 \%$ reduction in attempt risk among those with ideation $(\mathrm{RR}=0.18$; $95 \% \mathrm{CI}: 0.04$, 0.73). This would be associated with potential prevention of 100 cases of ideation per 1,000 trans persons $(\mathrm{cPAR}=0.10)$, and a further prevention of 220 attempts per 1,000 trans persons considering suicide (cPAR = 0.22). Among sources of strong support for gender, only support from parents was statistically significantly associated with reduced risk, with $\mathrm{RR}=0.43$ (95\% CI: 0.26, 0.73 ) for past-year ideation, and no additional statistically significant effect on the risk of attempts among those with ideation. At a population level, this corresponds to potential prevention of 170 trans persons per $1,000(\mathrm{cPAR}=0.17)$ from seriously considering suicide (and thus also reducing the risk of attempt through lowering the proportion at risk). Interestingly, strong support from leaders such as supervisors or teachers was significantly associated with an increased risk of attempts among those with ideation $(\mathrm{RR}=5.24 ; 95 \% \mathrm{CI}$ : $2.20,12.46)$. Having one or more identity documents concordant with lived gender was significantly associated with reductions in past-year ideation $(R R=0.56 ; 95 \%$ CI: $0.35,0.90)$ and attempts $(\mathrm{RR}=0.26,95 \% \mathrm{CI}$ : 0.11 , 0.62 ), with the potential to prevent 90 cases of ideation per 1,000 trans persons $(\mathrm{cPAR}=0.09)$, and 230 attempts per 1,000 with ideation $(\mathrm{cPAR}=0.23)$. Religiosity was not associated with suicidality. 
Table 1 Weighted background characteristics of trans people in Ontario, Canada $(n=380)$

\begin{tabular}{|c|c|c|}
\hline \multirow[t]{2}{*}{ Background variables } & \multicolumn{2}{|l|}{$n=380$} \\
\hline & $\overline{\%}$ or $\bar{x}$ & $95 \% \mathrm{Cl}$ \\
\hline Age, years $(\bar{x})$ & 32.7 & $(30.5,35.0)$ \\
\hline \multicolumn{3}{|l|}{ Gender spectrum (\%) } \\
\hline Female-to-male spectrum & 52.6 & $(44.4,60.8)$ \\
\hline Male-to-female spectrum & 47.4 & $(39.2,55.6)$ \\
\hline \multicolumn{3}{|l|}{ Gender fluidity (\%) } \\
\hline Primarily fluid or third gender identity & 17.7 & $(11.3,24.1)$ \\
\hline Primarily masculine or feminine identity & 82.3 & $(75.9,88.7)$ \\
\hline \multicolumn{3}{|l|}{ Ethnoracial group (\%) } \\
\hline Aboriginal & 6.6 & $(3.2,9.9)$ \\
\hline Non-Aboriginal white & 77.3 & $(71.0,83.6)$ \\
\hline Non-Aboriginal racialized & 16.1 & $(10.6,21.7)$ \\
\hline \multicolumn{3}{|l|}{ Place of birth (\%) } \\
\hline Canada & 80.3 & $(74.1,86.6)$ \\
\hline Outside of Canada & 19.7 & $(13.4,25.9)$ \\
\hline \multicolumn{3}{|l|}{ Sexual orientation (\%) } \\
\hline Lesbian, gay, bisexual or MSMNWSW & 66.7 & $(59.2,74.2)$ \\
\hline Straight & 33.3 & $(25.8,40.8)$ \\
\hline \multicolumn{3}{|l|}{ Region of residence (\%) } \\
\hline Southeastern Ontario & 10.8 & $(5.9,15.7)$ \\
\hline South Central Ontario & 16.4 & $(10.1,22.7)$ \\
\hline Metropolitan Toronto & 38.3 & $(30.3,46.3)$ \\
\hline Southwestern Ontario & 27.2 & $(18.7,35.8)$ \\
\hline Northern Ontario & 7.3 & $(2.9,11.6)$ \\
\hline Visual, hearing, communication or mobility disability (\%) & 12.4 & $(8.2,16.7)$ \\
\hline Parental status (young or grown children) (\%) & 25.6 & $(18.2,32.9)$ \\
\hline Strong religious upbringing (\%) & 23.7 & $(16.8,30.7)$ \\
\hline Childhood physical or sexual abuse (\%) & 70.7 & $(63.5,78.0)$ \\
\hline Major mental health disorder (\%) & 19.1 & $(13.4,24.7)$ \\
\hline Living with chronic illness or chronic pain (\%) & 18.0 & $(12.1,23.9)$ \\
\hline
\end{tabular}

Both transphobia variables in the analysis were associated with ideation and attempts, with lower transphobia associated with reduced risk. Lower overall transphobia $\left(10^{\text {th }}\right.$ percentile vs. $\left.90^{\text {th }}\right)$ was statistically significantly associated with a $66 \%$ relative risk reduction of past-year ideation ( $R R=0.34 ; 95 \% \mathrm{CI}: 0.17,0.67)$ and an additional $76 \%$ relative risk reduction $(\mathrm{RR}=0.24 ; 95 \% \mathrm{CI}$ : $0.07,0.82)$ for attempts. This represents a potential prevention of 160 cases of ideation per 1,000 trans persons (cPAR $=0.16$ ), and potential prevention of 200 attempts per 1,000 with ideation $(\mathrm{cPAR}=0.20)$.
Table 2 Means or frequencies of intervenable variables (social support, transphobia, and transition) and suicidality among trans people in Ontario, Canada $(n=380)$

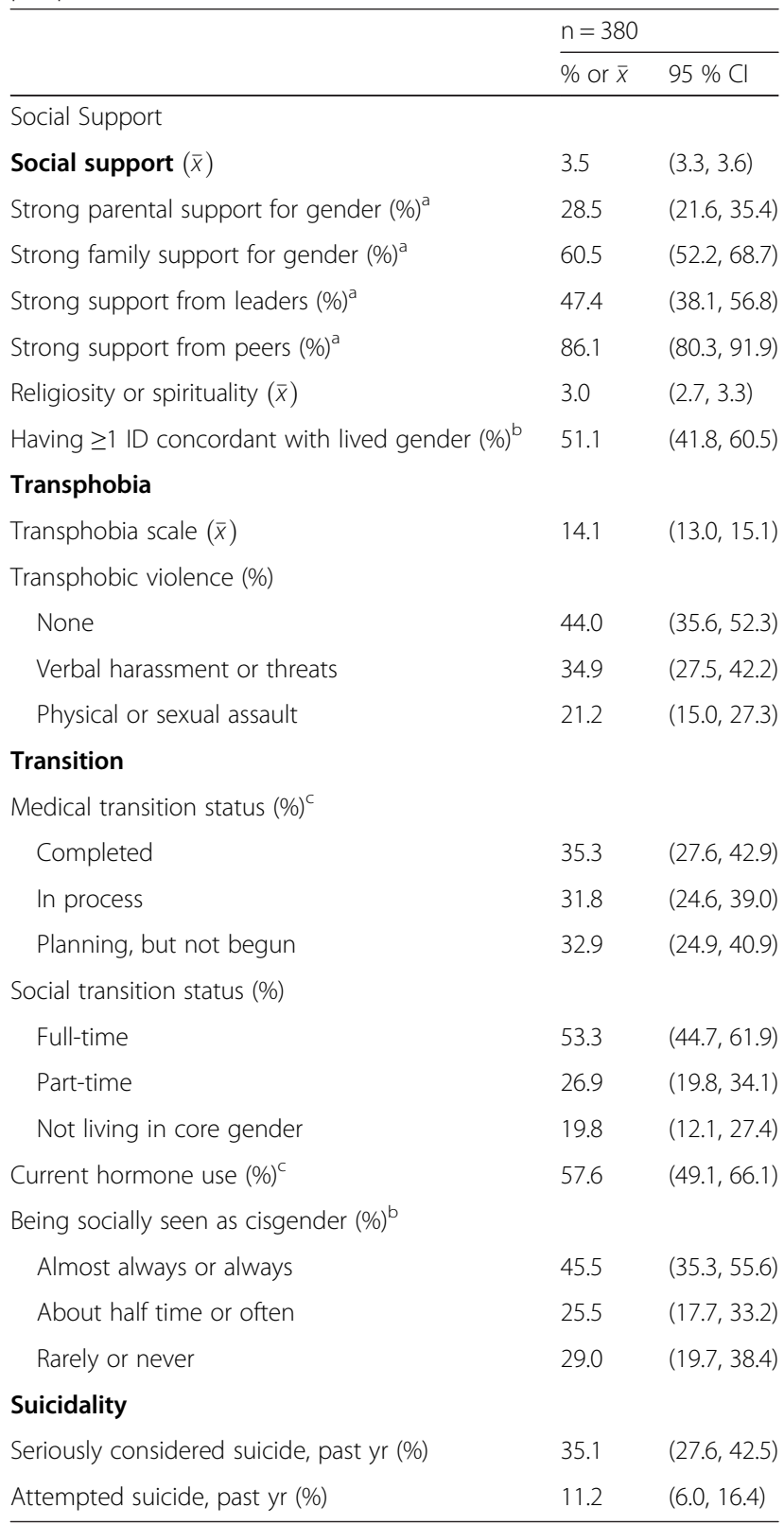

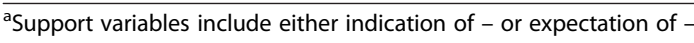
strong support

bamong those living full-time in a non-fluid gender $(n=251)$

camong those reporting need to medically transition sex $(n=346)$

Medical transition variables, but not social transition or being perceived as cisgender, were associated with suicidality. Among those who desired medical transition, those on hormone therapy were about half as likely to have seriously considered suicide $(\mathrm{RR}=0.52 ; 95 \% \mathrm{CI}$ : $0.37,0.75)$. The process of medically transitioning overall was more complex, with a monotonic reduction in suicide ideation from planning to transition vs. being in 
Table 3 Model-standardized risks for intervenable variables on suicidal ideation among trans people in Ontario, Canada $(n=380)$

\begin{tabular}{|c|c|c|c|c|c|c|}
\hline \multirow[t]{2}{*}{ Potential intervention factor } & \multirow[t]{2}{*}{ Number } & \multirow{2}{*}{$\begin{array}{l}R_{F}{ }^{a} \\
R_{1}{ }^{b} \\
R_{0}{ }^{c}\end{array}$} & \multicolumn{2}{|c|}{ Model-standardized RR ${ }^{d}$} & \multirow{2}{*}{$\begin{array}{l}\text { Counterfactual population } \\
\text { attributable risk }\left(R_{F}-R_{1}\right)^{f}\end{array}$} & \multirow{2}{*}{$\begin{array}{l}\text { Counte } \\
\text { attribut }\end{array}$} \\
\hline & & & $\mathrm{RR}$ & $95 \% \mathrm{Cl}^{\mathrm{e}}$ & & \\
\hline \multicolumn{7}{|l|}{ Social inclusion } \\
\hline Social support & 377 & 0.34 & & & & \\
\hline 90th percentile (4.895) & & 0.24 & 0.51 & $(0.28,0.94)$ & 0.10 & $29 \%$ \\
\hline 10th percentile (1.947) & & 0.47 & 1.00 & - & & \\
\hline Any strong parental support for gender ${ }^{\mathrm{h}}$ & 324 & 0.36 & & & & \\
\hline Yes & & 0.19 & 0.43 & $(0.26,0.73)$ & 0.17 & $47 \%$ \\
\hline No & & 0.43 & 1.00 & - & & \\
\hline Any strong family support for gender ${ }^{\mathrm{h}}$ & 368 & 0.35 & & & & \\
\hline Yes & & 0.29 & 0.66 & $(0.43,1.00)$ & & \\
\hline No & & 0.44 & 1.00 & - & & \\
\hline Any strong support from leaders ${ }^{\mathrm{h}}$ & 259 & 0.32 & & & & \\
\hline Yes & & 0.32 & 1.02 & $(0.62,1.48)$ & & \\
\hline No & & 0.32 & 1.00 & - & & \\
\hline Any strong support from peers ${ }^{h}$ & 366 & 0.35 & & & & \\
\hline Yes & & 0.33 & 0.67 & $(0.40,1.11)$ & & \\
\hline No & & 0.49 & 1.00 & - & & \\
\hline Religiosity or spirituality & 376 & 0.35 & & & & \\
\hline 90th percentile (5) & & 0.29 & 0.69 & $(0.42,1.15)$ & & \\
\hline 10th percentile (1) & & 0.41 & 1.00 & - & & \\
\hline Having $\geq 1$ ID concordant with lived gender' & 254 & 0.33 & & & & \\
\hline Yes & & 0.24 & 0.56 & $(0.35,0.90)$ & 0.09 & $27 \%$ \\
\hline No & & 0.43 & 1.00 & - & & \\
\hline \multicolumn{7}{|l|}{ Transphobia } \\
\hline Transphobia scale & 374 & 0.34 & & & & \\
\hline 10th percentile (5) & & 0.18 & 0.34 & $(0.170 .67)$ & 0.16 & $47 \%$ \\
\hline 90th percentile (23) & & 0.52 & 1.00 & - & & \\
\hline Transphobic harassment and violence & 380 & 0.35 & & & & \\
\hline None & & 0.34 & 0.68 & $(0.41,1.13)$ & 0.01 & $3 \%$ \\
\hline Verbal harassment or threats & & 0.27 & 0.54 & $(0.35,0.85)$ & & \\
\hline Physical or sexual assault & & 0.50 & 1.00 & - & & \\
\hline
\end{tabular}


Table 3 Model-standardized risks for intervenable variables on suicidal ideation among trans people in Ontario, Canada $(\mathrm{n}=380)(\mathrm{Continued})$

\section{Transition}

\section{Medical transition status}

Completed

In process

Planning, but not begun

Current hormone use

Yes

No

Social transition status

Full-time

Part-time

Not living in core gender

Being socially seen as cisgenderi

Almost always or always

About half time or often

Rarely or never
346

0.21

0.40

0.56

306

0.38

0.28

0.53

378

0.35

0.32

0.33

0.49

223

0.34
0.38

0.71

1.00

0.52

1.00

0.64

0.68

1.00

0.26

0.46

0.36

\section{$(0.22,0.66)$}

$(0.48,1.05)$

$(0.37,0.75)$

$26 \%$

Risks are standardized to sociodemographic factors, childhood trauma factors and major health-related background factors. These included: age, gender spectrum, gender fluidity, ethno-racial group, immigration history, sexual orientation, region of province, disability status, parental status, religious upbringing, childhood sexual or physical abuse, diagnosis with major mental health disorder (excluding depression or anxiety), and chronic illness or pain

${ }^{\mathrm{a}} \mathrm{R}_{\mathrm{F}}=$ estimated risk of past-year suicidal ideation in the factual trans population of Ontario

${ }^{\mathrm{b}} \mathrm{R}_{1}=$ model-standardized estimated risk of past-year suicidal ideation in the trans population of Ontario, under the same distribution of background factors, but where all members have a positive value of the potential intervention (e.g., high support, no transphobic violence)

${ }^{c} \mathrm{R}_{0}=$ model-standardized estimated risk of past-year suicidal ideation in the trans population of Ontario, under the same distribution of background factors, but where all members have a negative value of the potential intervention (e.g., low support, exposure to transphobic violence)

${ }^{\mathrm{d}}$ Will vary slightly from $\mathrm{R}_{1} / \mathrm{R}_{0}$ as are calculated as average of individual marginal risk ratios, rather than the ratio of model-standardized risks

${ }^{9} 95 \%$ confidence intervals from Taylor series linearization methods in SUDAAN

${ }^{\mathrm{f}}$ Counterfactual population attributable risk = potential proportion of population protected from suicidal ideation by a hypothetical move from population levels of this factor to an intervention level

${ }^{9}$ Counterfactual population attributable risk proportion = potential proportion of outcomes that could be averted under a change in exposure frequency

hSupport variables include either indication of - or expectation of - strong support

'among those living full-time in a non-fluid gender $(n=251)$

Jamong those reporting need to medically transition $\operatorname{sex}(n=346)$ 
Table 4 Model-standardized risks for intervenable variables on suicide attempts among trans people who have seriously considered suicide, Ontario, Canada ( $\mathrm{n}=110$ )

\begin{tabular}{|c|c|c|c|c|c|c|}
\hline \multirow[t]{2}{*}{ Potential intervention factor } & \multirow[t]{2}{*}{ number } & \multirow{2}{*}{$\begin{array}{l}R_{F}{ }^{a} \\
R_{1}{ }^{b} \\
R_{0}{ }^{c}\end{array}$} & \multicolumn{2}{|c|}{ Model-standardized RR ${ }^{d}$} & \multirow{2}{*}{$\begin{array}{l}\text { Counterfactual population } \\
\text { attributable risk }\left(R_{F}-R_{1}\right)^{f}\end{array}$} & \multirow{2}{*}{$\begin{array}{l}\text { Counter } \\
\text { attributa }\end{array}$} \\
\hline & & & $\mathrm{RR}$ & $95 \% \mathrm{Cl}^{\mathrm{e}}$ & & \\
\hline \multicolumn{7}{|l|}{ Social inclusion } \\
\hline Social support & 109 & 0.30 & & & & \\
\hline 90th percentile (4.895) & & 0.08 & 0.18 & $(0.04,0.73)$ & 0.22 & $73 \%$ \\
\hline 10th percentile (1.947) & & 0.47 & 1.00 & - & & \\
\hline Any strong parental support for gender ${ }^{h}$ & 99 & 0.31 & & & & \\
\hline Yes & & 0.10 & 0.29 & $(0.07,1.24)$ & & \\
\hline No & & 0.35 & 1.00 & - & & \\
\hline Any strong family support for gender ${ }^{h}$ & 106 & 0.30 & & & & \\
\hline Yes & & 0.27 & 0.81 & $(0.41,1.62)$ & & \\
\hline No & & 0.33 & 1.00 & - & & \\
\hline Any strong support from leaders ${ }^{h}$ & 72 & 0.34 & & & & \\
\hline Yes & & 0.58 & 5.24 & $(2.20,12.46)$ & -0.24 & $\mathrm{n} / \mathrm{a}$ \\
\hline No & & 0.11 & 1.00 & - & & \\
\hline Any strong support from peers ${ }^{h}$ & 106 & 0.30 & & & & \\
\hline Yes & & 0.32 & 1.34 & $(0.43,4.23)$ & & \\
\hline No & & 0.24 & 1.00 & - & & \\
\hline Religiosity or spirituality & 109 & 0.30 & & & & \\
\hline 90th percentile (5) & & 0.20 & 0.52 & $(0.12,2.18)$ & & \\
\hline 10th percentile (1) & & 0.39 & 1.00 & - & & \\
\hline Having $\geq 1$ ID concordant with lived gender' & 55 & 0.37 & & & & \\
\hline Yes & & 0.14 & 0.26 & $(0.11,0.62)$ & 0.23 & $62 \%$ \\
\hline No & & 0.54 & 1.00 & - & & \\
\hline \multicolumn{7}{|l|}{ Transphobia } \\
\hline Transphobia scale & 108 & 0.31 & & & & \\
\hline 10th percentile (5) & & 0.11 & 0.24 & $(0.07,0.82)$ & 0.20 & $65 \%$ \\
\hline 90th percentile (23) & & 0.45 & 1.00 & - & & \\
\hline Transphobic harassment and violence & 110 & 0.32 & & & & \\
\hline None & & 0.18 & 0.30 & $(0.08,1.16)$ & 0.14 & $44 \%$ \\
\hline Verbal harassment or threats & & 0.18 & 0.31 & $(0.11,0.83)$ & & \\
\hline Physical or sexual assault & & 0.59 & 1.00 & - & & \\
\hline
\end{tabular}


Table 4 Model-standardized risks for intervenable variables on suicide attempts among trans people who have seriously considered suicide, Ontario, Canada ( $\mathrm{n}=110$ ) (Continued)

\begin{tabular}{|c|c|c|c|c|c|c|}
\hline \multicolumn{7}{|l|}{ Transition } \\
\hline Medical transition status ${ }^{j}$ & 100 & 0.35 & & & & \\
\hline Completed & & 0.11 & 0.51 & $(0.07,3.74)$ & 0.24 & $69 \%$ \\
\hline In process & & 0.65 & 2.91 & $(1.47,5.76)$ & & \\
\hline Planning, but not begun & & 0.22 & 1.00 & - & & \\
\hline Current hormone use $\mathrm{e}^{\mathrm{j}}$ & 98 & 0.36 & & & & \\
\hline Yes & & 0.30 & 0.76 & $(0.41,1.39)$ & & \\
\hline No & & 0.40 & 1.00 & - & & \\
\hline Social transition status & 109 & 0.31 & & & & \\
\hline Full-time & & 0.45 & 5.30 & $(0.66,42.68)$ & & \\
\hline Part-time & & 0.21 & 2.53 & $(0.34,18.60)$ & & \\
\hline Not living in core gender & & 0.08 & 1.00 & - & & \\
\hline Being socially seen as cisgender' & 56 & 0.36 & & & & \\
\hline Almost always or always & & 0.48 & 0.98 & $(0.58,1.64)$ & & \\
\hline About half time or often & & 0.14 & 0.28 & $(0.02,3.26)$ & & \\
\hline Rarely or never & & 0.49 & 1.00 & - & & \\
\hline
\end{tabular}

Risks are standardized to sociodemographic factors, childhood trauma factors and major health-related background factors. These included: age, gender spectrum, gender fluidity, ethno-racial group, immigration history, sexual orientation, region of province, disability status, parental status, religious upbringing, childhood sexual or physical abuse, diagnosis with major mental health disorder (excluding depression or anxiety),

and chronic illness or pain
${ }^{a} R_{F}=$ estimated risk of past-year suicidal ideation in the factual trans population of Ontario

${ }^{\mathrm{b}} \mathrm{R}_{1}=$ model-standardized estimated risk of past-year suicidal ideation in the trans population of Ontario, under the same distribution of background factors, but where all members have a positive value of the potential intervention (e.g., high support, no transphobic violence)

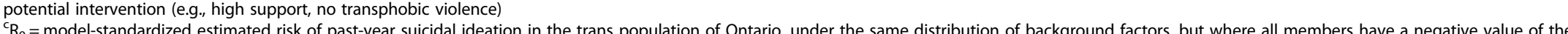
$\mathrm{R}_{0}=$ model-standardized estimated risk of past-year suicidal ideation in the tor

${ }^{d}$ Will vary slightly from $R_{1} / R_{0}$ as are calculated as average of individual marginal risk ratios, rather than the ratio of model-standardized risks

Will vary slighty from $R_{1} / R_{0}$ as are calculated as average of individual marginal is

${ }^{\mathrm{f} C o u n t e r f a c t u a l}$ population attributable risk = potential proportion of population protected from suicidal ideation by a hypothetical move from population levels of this factor to an intervention level

${ }^{9}$ Counterfactual population attributable risk proportion = potential proportion of outcomes that could be averted under a change in exposure frequency

${ }^{\text {h }}$ Support variables include either indication of - or expectation of - strong support

among those living full-time in a non-fluid gender $(n=57)$

Jamong those reporting need to medically transition sex $(n=100)$ 
process, vs. completing. However, among the sub-group with ideation, being in the process of transitioning was significantly associated with increased risk of an attempt $(\mathrm{RR}=2.91 ; 95 \% \mathrm{CI}: 1.48,5.76)$ in comparison with those who were planning to transition but had not yet begun. We did not observe an increased risk in this sub-group among those who completed a medical transition $(\mathrm{RR}=$ $0.51 ; 0.07,3.74)$. Completing a medical transition had beneficial individual and population effects. It was associated with a $62 \%$ relative risk reduction $(R R=0.38$; $95 \%$ CI: $0.22,0.66)$ in ideation. On a trans population level, to facilitate completion of medical transition (when desired) would correspond to preventing 170 cases of ideation per year per 1,000 trans persons $(\mathrm{cPAR}=0.17)$, representing $44 \%$ of ideation $(\mathrm{c} \% \mathrm{PAR}=$ 0.44 ), and further preventing 240 attempts per 1,000 with ideation $(\mathrm{cPAR}=0.24)$ or $69 \%$ of attempts in this group $(\mathrm{c} \% \mathrm{PAR}=0.69)$.

\section{Discussion}

Our findings provide evidence that social inclusion (social support, gender-specific support from parents, identity documents), protection from transphobia (interpersonal, violence), and undergoing medical transition have the potential for sizeable effects on the high rates of suicide ideation and attempts in trans communities. In contrast, we did not find statistically significant effects for social transition, gender support from sources other than parents, or religiosity/spirituality, other than an unexpected finding regarding strong gender support from leaders. Given that statistical power was not high, as evidenced by the width of our confidence intervals, a lack of statistical significance does not mean that these other factors should be dismissed, as smaller effects may exist below the threshold for detection.

Our results provide support for the potentially strong impact of trans-specific discrimination or harassment (e.g., experiences of transphobia), interpersonal factors (e.g., strong parental support for gender identity or expression) and structural factors (e.g., having an identity document with a gender marker concordant with one's lived gender) on suicide ideation or attempts. This reinforces our earlier descriptive findings that risk of suicide ideation and attempts varied greatly among trans people [2], and reinforces the need to look beyond proximal determinants toward sites of early prevention or intervention. It is not clear to what extent results from this study may also apply to gender non-conforming cisgender persons, but we note that among sexual minority youth, early gender non-conformity has been associated with increased suicidal behaviour or risk, a process that may be mediated by gender harassment or bullying [53-55], or by parental disapproval of gender expression [55].

The large effect sizes observed support the possibility for preventing suicidal ideation and attempts in a large number of individuals. Using the transphobia results as an example, combining the population effects of a reduction in ideation and a reduction in attempt risk among the reduced cases of ideation, and given a population estimate of 53,500 trans adults in Ontario [26], we would estimate that reducing experiences of transphobia could prevent 8,560 trans persons in the province from experiencing suicidal ideation and 4,601 persons from a suicide attempt within a year.

Our results represent the most detailed analysis of this issue to date; our study was based on a respondentdriven sample of trans people from a large provincial geographic area. The analysis takes account of differential probability of recruitment related to differences in network size, but other biases unrelated to network size may remain [56]. Our use of past-year suicide-related measures represents an improvement over studies that used lifetime measures, as we are able to analyse impact on recent or current risk, which is most relevant to prevention. However, temporality remains a concern. It is possible that some potential causes occurring in the past year followed rather than preceded the outcome. This is one potential explanation of the unusual finding of support from a leader (teacher, supervisor, institution) being associated with increased suicide attempts among those with ideation, in that an attempt may trigger the involvement of leaders. Moreover, as we were unable to determine the exact sequences of events for each participant, it is likely that we have partially controlled for some mediating effects or not controlled for some confounding. For example, borderline personality disorder is adjusted for as a confounder, though it is possible that for some participants its etiology includes experiences of transphobia such as those we assess, and it may thus play a mediating role. Despite these limitations, we attempted to address temporality within a cross-sectional design through time designations within questionnaire items (e.g., childhood abuse prior to the age for inclusion in this study) and use of past-year outcomes.

Our finding that completing a medical transition was associated with reduced risk has implications for interpretation of existing studies on completed suicides. Because trans people are not identifiable in death records, and because completed suicides may occur among those who know they are trans but are not known by family members to be trans, valid studies of completed suicides have only been done where patient records from gender clinics have been matched to population death records (e.g., in Sweden [15]). Our results suggest these estimates of completed suicide among those who have medically transitioned likely underestimate the risk of suicide among broader trans communities.

As all surveys are, by definition, studies of survivors, survival bias remains an issue. Frequencies for attempts 
will likely be underestimated. Factors that predict lethality may be missed, if those who completed suicide differ from those who survived attempts. Given that we assessed suicide attempts only among those who indicated past-year serious consideration, our data may also have missed additional attempts that were impulsive and unplanned. Moreover, past-year prevalence may not represent a first incident of suicide ideation or attempt; thus, this analysis cannot distinguish between factors that lead one to first become suicidal versus to continue being suicidal.

Proximal factors theorized and demonstrated to increase risk of suicide ideation and/or attempts (e.g., risk factors from epidemiological research and interpersonal factors from Joiner's Interpersonal Model [43]) were conceptualized as mediators, but not included in these analyses. Moreover, our analysis could not disaggregate effects of intervenable variables on other intervenable variables. For example, it is possible that increased parental support for gender may affect whether or not someone is able to medically transition; it is also possible that medical transition results in increased parental support for gender, as parents are able to more clearly see their child in their felt gender. These areas represent opportunities for future research. In general, suicide research regarding gender and sexual minorities has tended to overlook existing theoretical frameworks within suicidology [57], though they are not incompatible with other frameworks or methods. Future research with trans populations could draw on interdisciplinary theories as well as evidence from trans-specific and broader population research on suicide ideation and attempts to study mediated pathways.

Future prospective cohort studies of broadly defined trans populations are needed to alleviate many of the limitations of this and other studies. With prospective data, we may be able to differentiate between factors that cause initial ideation and factors that prolong its duration, as well as those that lead to first and repeated attempts. We could also begin to study completed suicides in a non-clinical trans population, at least among those who are willing to identify as trans to researchers. Moreover, with clear information on temporality, we would be able to design better controlled and more valid analyses, and to examine mediated pathways (including pathways between intervenable factors as well as proximal factors) to better understand the process through which social marginalization may impact suicide ideation and attempt.

Our goal of evaluating intervenable factors should be interpreted as a screening of potential strategies rather than an analysis of actual population intervention effects. While background factors are structured to represent those that are in the past, unchangeable, or not likely to change in response to other factors in the model, our analytic approach then considers intervenable factors singly; it was not possible to tease apart causal pathways among these factors and combining them into one model would by default serve to prioritize the proximal causal factors while reducing the effect sizes of other potentially important causes [58] (a general effect of multivariable models that is not often explicated but is commonly understood with regard to control for a mediator reducing a causal effect $[59,60])$. Depending upon inter-individual variation, as in all individual-level studies, also results in an inability to detect simultaneous effects at the group level [61]. For example, reducing transphobic assaults from the current prevalence of 21.2 to $0 \%$ may affect suicide risk not only by saving individuals from the trauma of hate-based assault, but may have additional effects on these individuals and others based on living in a society where transphobic assaults do not occur, versus where they are common.

\section{Conclusions}

Our findings support a strong effect for social exclusion, discrimination and lack of medical transition (for those needing it) on suicide ideation and attempts, and potentially on the survival of trans persons. This adds support to the larger discussion regarding social impacts on suicide risk in groups experiencing marginalization, such as Indigenous communities and sexual minorities. Our team has previously published recommendations for suicide prevention efforts with trans persons, based on descriptive analyses of these data [2]. The present analysis provides stronger support for those recommendations, including attention to social support and protection from discrimination, by showing that these effects remain after adjusting for potential confounding by background. It also suggests additional targets for intervention. Specifically, while gender recognition is recognized as a human right for trans people in Ontario [62], we have provided the first evidence of its potential to reduce suicidality. Since our data were collected, the surgical requirement for changing the sex/gender designation on an Ontario birth certificate has been eliminated. Such legal and policy changes can be considered public health interventions worthy of longerterm evaluation. In addition, parental support has been previously associated with reduced suicide risk for sexual minority [63] and trans [64] youth, but our results demonstrate the importance of parental support for gender identity among adults, suggesting a need for all-ages family interventions. Finally, we found that among those reporting a need to medically transition through hormones and/ or surgeries, suicidality was substantially reduced among those who had completed a medical transition (this involved varying procedures based on personal needs [16]). Despite potentially large reductions in risk for those 
completing medical transition, the period of being in process did not represent a clear mid-point in risk. While suicidal ideation was significantly reduced for those in process versus those who were planning to transition but had not begun, among the sub-group considering suicide the attempt rate was highest among those in process. These results call into question the safety of clinical practices that delay transition treatments until depressive symptoms or suicidality are well-controlled, and of procedural practices that require or result in long delays in the medical transition process, but also suggest need for supports for those who may feel suicidal while in the process of transitioning.

Our findings strongly suggest that interventions aimed at increasing social inclusion, reducing transphobic discrimination and violence, and facilitating access to medical transition should be considered as part of a comprehensive approach to suicide prevention in trans populations, and evaluated to assess effectiveness. Such interventions need not supplant individual-level or therapeutic approaches (e.g., psychotherapy, crisis services), but have the potential to reduce suicide ideation and attempts by targeting stigma and social exclusion as fundamental causes of disparities.

\section{Competing interests}

The authors declare that they have no competing interests.

\section{Authors' contributions}

GRB, JP, RT and RH planned and undertook the survey. GRB designed and conducted this analysis. GRB and AIS drafted the manuscript. All authors contributed to the theoretical model, interpretation of results, and editing of the manuscript. All authors read and approved the final manuscript.

\section{Acknowledgements}

This work was supported by an operating grant from the Canadian Institutes of Health Research, Institute of Gender and Health [Funding Reference \#MOP-106478]. Ayden Scheim and Jake Pyne were supported by Trudeau Foundation and Vanier Canada Graduate Scholarships. Partners in Trans PULSE included the Sherbourne Health Centre (Toronto), The 519 Church Street Community Centre (Toronto), The University of Western Ontario (London), Wilfrid Laurier University (Waterloo), and Rainbow Health Ontario. The Trans PULSE Steering Committee members were Greta Bauer, Robb Travers, Rebecca Hammond, Anjali K, Matthias Kaay, Jake Pyne, Nik Redman, Kyle Scanlon (deceased), and Anna Travers. The authors wish to acknowledge Xuchen Zong for assistance with gathering literature, Anna Travers for substantive comments on the theoretical model, the 16 Community Engagement Team members and other Trans PULSE contributors who worked to develop and promote the survey, the 89 first-phase participants, and the 433 survey participants.

Finally, the authors wish to dedicate this work to our colleague Kyle Scanlon, who initiated this study, fundamentally shaped its form, and who we lost to suicide in 2012.

\footnotetext{
Author details

'Epidemiology \& Biostatistics, Schulich School of Medicine \& Dentistry, The University of Western Ontario, London, Canada. ${ }^{2}$ School of Social Work \& Gender Studies and Feminist Research Program, McMaster University, Hamilton, Canada. ${ }^{3}$ Health Sciences Program \& Department of Psychology, Wilfrid Laurier University, Waterloo, Canada. ${ }^{4}$ Sherbourne Health Centre, Toronto, Canada.
}

Received: 10 October 2014 Accepted: 22 May 2015

Published online: 02 June 2015

\section{References}

1. Conron KJ, Scott G, Stowell GS, Landers SJ. Transgender health in Massachusetts: results from a household probability sample of adults. Am J Public Health. 2012;102:118-22.

2. Bauer GR, Pyne J, Francino MC, Hammond R. Suicidality among trans people in Ontario: implications for social work and social justice/La suicidabilité parmi les personnes trans en Ontario: implications en travail social et en justice sociale. Serv Soc. 2013;59:35-62.

3. Motmans J, de Biolley I, Debunne S. Being Transgender in Belgium: Mapping the Social and Legal Situation of Transgender People. Brussels: Institute for the Equality of Women and Men; 2010. http://igvmiefh.belgium.be/nl/binaries/34\%20-\%20Transgender_ENG_tcm336-99783.pdf. Accessed 15 Sept 2014.

4. Whittle S, Turner L, Combs R, Rhodes S. Transgender EuroStudy: Legal Survey and Focus on the Transgender Experience of Health Care. Brussels, Belgium: ILGA Europe; 2008. http://tgeu.org/sites/default/files/eurostudy.pdf. Accessed 15 Sept 2014.

5. McNeil J, Bailey L, Ellis S, Morton J, Regan M. Trans Mental Health Study 2012. Edinburgh: Equality Network; 2012. http://www.scottishtrans.org/ Uploads/Resources/trans_mh_study.pdf. Accessed 15 Sept 2014.

6. Clements-Nolle K, Marx R, Katz M. Attempted suicide among transgender persons: the influence of gender-based discrimination and victimization. J Homosex. 2006;51:53-69.

7. Grant JM, Mottet LA, Tanis J, Harrison J, Herman JL, Keisling M. Injustice at Every Turn: A Report of the National Transgender Discrimination Survey. Washington, D.C.: National Center for Transgender Equality and National Gay and Lesbian Task Force; 2011. http://www.thetaskforce.org/downloads/ reports/reports/ntds_full.pdf. Accessed 15 Sept 2014.

8. Rhodes AE, Bethell J, Bondy SJ. Suicidality, depression, and mental health service use in Canada. Can J Psychiatry. 2006;51:35-41.

9. Blackmore ER, Munce S, Weller I, Zagorski B, Stansfeld SA, Stewart DE, et al. Psychosocial and clinical correlates of suicidal acts: results from a national population survey. Br J Psychiatry. 2008;192:279-84.

10. Haas AP, Eliason M, Mays VM, Mathy RM. Suicide and suicide risk in lesbian, gay, bisexual, and transgender populations: review and recommendations. J Homosex. 2010;58:10-51.

11. Harris EC, Barraclough B. Suicide as an outcome for mental disorders: a meta-analysis. Br J Psychiatry. 1997;170:205-28.

12. Nock MK, Borges G, Bromet EJ, Cha CB, Kessler RC, Lee S. Suicide and suicidal behavior. Epidemiol Rev. 2008:30:133-54.

13. Maguen S, Shipherd JC. Suicide risk among transgender individuals. Psychol Sexual. 2010;1:34-43.

14. Terada S, Matsumoto Y, Sato T, Okabe N, Kishimoto Y, Uchitomi Y. Suicidal ideation among patients with gender identity disorder. Psychiatry Res. 2011;190:159-62.

15. Dhejne $C$, Lichtenstein $P$, Boman $M$, Johansson ALV, Långström $N$, Landén $M$. Long-term follow-up of transsexual persons undergoing sex reassignment surgery: cohort study in Sweden. PLoS One. 2011;6, e16885.

16. Scheim Al, Bauer GR. Sex and gender diversity among transgender persons in Ontario, Canada: results from a respondent-driven sampling survey. J Sex Res. 2015;52:1-14.

17. Colizzi M, Costa R, Todarello O. Transsexual patients' psychiatric comorbidity and positive effect of cross-sex hormonal treatment on mental health: results from a longitudinal study. Psychoneuroendocrinology. 2014;39:65-73.

18. Heylens G, Verroken C, De Cock S, T'Sjoen G, De Cuypere G. Effects of different steps in gender reassignment therapy on psychopathology: a prospective study of persons with a gender identity disorder. J Sex Med. 2011;11:119-26.

19. Rotondi NK, Bauer GR, Scanlon K, Kaay M, Travers R, Travers A. Nonprescribed hormone use and self-performed surgeries: "do-it-yourself" transitions in transgender communities in Ontario, Canada. Am J Public Health. 2013;103:1830-6.

20. Asscheman H, Giltay EJ, Megens JAJ, de Ronde W, van Trotsenburg MAA, Gooren LJG. A long-term follow-up study of mortality in transsexuals receiving treatment with cross-sex hormones. Eur J Endocrinol. 2011;164:635-42.

21. Marcellin RL, Bauer GR, Scheim Al. Intersecting impacts of transphobia and racism on HIV risk among trans persons of colour in Ontario, Canada. Ethnicity Inequal Health Soc Care. 2013;6:97-107.

22. Bauer GR, Hammond R, Travers R, Kaay M, Hohenadel KM, Boyce M. "I don't think this is theoretical; this is our lives": how erasure impacts health care for transgender people. J Assoc Nurses AIDS Care. 2009;20:348-61. 
23. Bockting WO, Miner MH, Swinburne Romine RE, Hamilton A, Coleman E. Stigma, mental health, and resilience in an online sample of the US transgender population. Am J Public Health. 2013;103:943-51.

24. Lombardi EL, Wilchins RA, Priesing D, Malouf D. Gender violence: transgender experiences with violence and discrimination. J Homosex. 2001:42:89-101.

25. Nemoto T, Bödeker B, Iwamoto M. Social support, exposure to violence and transphobia, and correlates of depression among male-to-female transgender women with a history of sex work. Am J Public Health. 2011;101:1980-8.

26. Stotzer RL. Violence against transgender people: a review of United States data. Aggress Violent Behav. 2009;14:170-9.

27. Bauer GR, Travers R, Scanlon K, Coleman TA. High heterogeneity of HIV-related sexual risk among transgender people in Ontario, Canada: a province-wide respondent-driven sampling survey. BMC Public Health. 2012;12:292

28. Testa RJ, Sciacca LM, Wang F, Hendricks ML, Boldblum P, Bradford J, et al. Effects of violence on transgender people. Prof Psychol Res Pr. 2012;43:452-9.

29. Moody C, Smith NG. Suicide protective factors among trans adults. Arch Sex Behav. 2013;42:739-52.

30. Rotondi NK, Bauer GR, Travers R, Travers A, Scanlon K, Kaay M. Depression in male-to-female transgender Ontarians. Can J Community Ment Health. 2011;30:113-33.

31. Rotondi NK, Bauer GR, Scanlon K, Kaay M, Travers R, Travers A. Prevalence of and risk and protective factors for depression in female-to-male transgender Ontarians. Can J Community Ment Health. 2011;30:135-55.

32. Nuttbrock LA, Bockting W, Rosenblum A, Hwahng S, Mason M, Macri M, et al. Gender abuse, depressive symptoms, and HIV and other sexually transmitted infections among male-to-female transgender persons: a three-year prospective study. Am J Public Health. 2013;103:300-7.

33. Nuttbrock LA, Bockting W, Rosenblum A, Mason M, Macri M, Becker J. Gender identity conflict/affirmation and major depression across the life course of transgender women. Int J Transgenderism. 2012;13:91-103.

34. Burton CM, Marshal MP, Chisolm DJ, Sucato GS, Friedman MS. Sexual minority-related victimization as a mediator of mental health disparities in sexual minority youth: a longitudinal analysis. J Youth Adolesc. 2013;42:394-402.

35. Liu RT, Mustanski B. Suicidal ideation and self-harm in lesbian, gay, bisexual, and transgender youth. Am J Prev Med. 2012;42:221-8.

36. Mereish EH, O'Cleirigh C, Bradford JB. Interrelationships between LGBT-based victimization, suicide, and substance use problems in a diverse sample of sexual and gender minorities. Psychol Health Med. 2014;19:1-13.

37. Diaz RM, Ayala G, Bein E, Henne J, Marin BV. The impact of homophobia, poverty, and racism on the mental health of gay and bisexual Latino men: findings from 3 US cities. Am J Public Health. 2001:91:927-32.

38. World Health Organization. Preventing Suicide: A Global Imperative. Geneva; 2014 http://apps.who.int/iris/bitstream/10665/131056/1/ 9789241564779_eng.pdf?ua=1\&ua=1. Accessed 15 Sept 2014.

39. Leenaars AA. Suicide among indigenous peoples: introduction and call to action. Arch Suicide Res. 2006;10:103-15.

40. Chandler MJ, Lalonde C. Cultural continuity as a hedge against suicide in Canada's First Nations. Transcult Psychiatry. 1999;35:191-219.

41. Elias B, Mignone J, Hall M, Hong SP, Hart L, Sareen J. Trauma and suicide behaviour histories among a Canadian indigenous population: an empirica exploration of the potential role of Canada's residential school system. Soc Sci Med. 2012;74:1560-9.

42. Meyer $\mathrm{H}$. Minority stress and mental health in gay men. J Health Soc Behav. 1995:36:38-56.

43. Joiner T. Why People Die by Suicide. Cambridge, MA: Harvard University Press; 2005

44. Van Orden KA, Witte TK, Cukrowicz KC, Braithwaite SR, Selby EA, Joiner TE. The interpersonal theory of suicide. Psychol Rev. 2010;117:575-600.

45. Warner A. Prevalence and risk factors for being underhoused among trans people in Ontario: a cross-sectional study. MSc thesis. The University of Western Ontario, Epidemiology \& Biostatistics; 2010.

46. Ontario Human Rights Commission. Policy and Guidelines on Racism and Discrimination. 2005. http://www.ohrc.on.ca/en/policy-and-guidelines-racismand-racial-discrimination/part-1---setting-context-understanding-race-racismand-racial-discrimination. Accessed 23 Mar 2015.

47. Sherbourne CD, Stewart A. The MOS social support survey. Soc Sci Med. 1991;32:705-14.
48. Volz E, Heckathorn DD. Probability based estimated theory for respondent driven sampling. J Off Stat. 2008;24:79-97.

49. Wejnert C. An empirical test of respondent-driven sampling: point estimates, variance, degree measures, and out-of-equilibrium data. Sociol Methodol. 2009;39:73-116.

50. SAS Institute Inc: SAS Version 9.3. Cary, NC; 2012

51. RTI Institute: SUDAAN Version 11.0.1. Research Triangle Park, NC; 2013.

52. Graubard Bl, Korn EL. Predictive margins with survey data. Biometrics. 1999:55:652-9.

53. Plöderl M, Fartacek R. Childhood gender nonconformity and harassment as predictors of suicidality among gay, lesbian, bisexual, and heterosexual Austrians. Arch Sex Behav. 2009;38:400-10

54. Friedman MS, Koeske GF, Silvestre AJ, Korr WS, Sites EW. The impact of gender-role nonconforming behavior, bullying, and social support on suicidality among gay male youth. J Adolesc Health. 2006;38:621-3.

55. D'Augelli AR, Grossman AH, Salter NP, Vasey JJ, Starks MT, Sinclair KO. Predicting the suicide attempts of lesbian, gay, and bisexual youth. Suicide Life Threat Behav. 2005;35(6):646-60.

56. McCreesh N, Frost S, Seeley J, Katongole J, Tarsh MN, Ndunguse R, et al. Evaluation of respondent-driven sampling. Epidemiology. 2012;23:138-47.

57. Plöderl M, Sellmeier M, Fartacek C, Pichler E-M, Fartacek R, Kralovec K. Explaining the suicide risk of sexual minority individuals by contrasting the minority stress model with suicide models. Arch Sex Behav. 2014:43:1559-70.

58. Weitkunat $\mathrm{R}$, Wildner M. Exploratory causal modeling in epidemiology: are all factors created equal? J Clin Epidemiol. 2002;55:436-44.

59. Baron RM, Kenny D. The moderator-mediator variable distinction in social psychological research: conceptual, strategic, and statistical considerations. J Pers Soc Psychol. 1986;51(6):1173-82.

60. Zhao X, Lynch Jr JG, Chen Q. Reconsidering Baron and Kenny: myths and truths about mediation analysis. J Consumer Res. 2010;37(2):197-206.

61. Schwartz S, Carpenter KM. The right answer for the wrong question: consequences of type III error for public health research. Am J Public Health. 1999:89:1175-80.

62. Ontario Human Rights Commission. Policy on Preventing Discrimination Because of Gender Identity and Gender Expression. Toronto, ON; 2014. http://www.ohrc.on.ca/en/policy-preventing-discrimination-because-genderidentity-and-gender-expression. Accessed 23 Mar 2015.

63. Ryan C, Russell S, Huebner D, Diaz R, Sanchez J. Family acceptance in adolescence and the health of LGBT young adults. J Child Adolesc Psychiatr Nurs. 2010;23:205-13.

64. Travers R, Bauer G, Pyne J, Bradley K, Gale L, Papadimitriou M. Impacts of Strong Parental Support for Trans Youth. Trans PULSE Project; 2012. http://transpulseproject.ca/research/impacts-of-strong-parental-supportfor-trans-youth/. Accessed 15 Sept 2014.

\section{Submit your next manuscript to BioMed Central and take full advantage of:}

- Convenient online submission

- Thorough peer review

- No space constraints or color figure charges

- Immediate publication on acceptance

- Inclusion in PubMed, CAS, Scopus and Google Scholar

- Research which is freely available for redistribution 